\title{
Augmentative and alternative communication (AAC) training provision for professionals in England
}

\begin{tabular}{|r|l|}
\hline Journal: & Journal of Enabling Technologies \\
\hline Manuscript ID & JET-10-2016-0023.R2 \\
\hline Manuscript Type: & Project Report \\
\hline Keywords: & $\begin{array}{l}\text { continuing professional development, training, augmentative and } \\
\text { alternative communication, international classification of functioning, } \\
\text { disability and health, survey, therapists }\end{array}$ \\
\hline \multicolumn{2}{|l}{} \\
\hline
\end{tabular}


Augmentative and alternative communication (AAC) training provision for professionals in England

\begin{abstract}
Purpose - This paper documents augmentative and alternative communication (AAC) training provision by clinical services in England.

Design/Methodology/Approach - A questionnaire was used to obtain the following information concerning AAC training provision; (i) frequency, length, type, content and cost, trainee occupations and numbers, and future training priorities, and (ii) information concerning training providers - service type, geographical area.

Findings - Ninety-eight clinical service training providers in England responded. Services commonly reported providing AAC training to speech and language therapists, teaching assistants and teachers. Training around 'use of specific AAC products, systems and technology' and 'introducing/awareness raising of AAC products' were rated as high priority for future training and were two of the three subject areas where services reported the highest percentage of training. Training was predominantly provided at a foundation (basic) level.

Originality/Value - There is no consensus on the amount or content of AAC training which professionals in England must receive. Evidence suggests that AAC training for prequalification professionals is limited and this paper has identified variation in the amount and type of post-qualification AAC training. While knowledge concerning specific AAC systems is necessary, focusing training primarily on this area may not address critical gaps in knowledge. There is a need for specific recommendations regarding AAC training for professionals in this field, to ensure professionals can fully support people who use AAC.

Key Words augmentative and alternative communication, training, continuing professional development, international classification of functioning, disability and health, survey, therapists

Paper Type Research Paper
\end{abstract}

\title{
1. Introduction
}

Augmentative and alternative communication (AAC) refers to communication methods that either supplement or substitute an individual's speech and/or writing (Clarke et al., 2016). These may be unaided (such as the use of manual signs) or aided (involving the use of communication devices external to the body, such as communication aid technologies). AAC strategies and tools are part of a fluid, multi-modal repertoire of resources that are used in every day communication interactions. It is estimated that approximately $0.5 \%$ of the population of England requires AAC intervention (Communication Champion, 2011; Creer et al., 2016).

The importance of AAC to the lives of children and adults is reflected through current education and health care funding and service delivery guidelines in England and Wales (Department for Education, 2013; NICE, 2016), through the reported experiences of people using AAC (Clarke \& McConachie, 2001) and a growing body of research evidence (Light \& McNaughton, 2012; Ganz, 2015). Consequently, there is an increasing requirement for 
professionals to maintain and enhance their knowledge and skills in supporting people using AAC. During the last 20 years there has been a marked growth in the diversity of AAC technology, partly due to the rapid expansion and adaptation of mainstream technologies, and ongoing developments in specialist technologies (Communication Matters, 2012).

\subsection{Training Need}

In the United Kingdom (UK), policy and research recommendations for AAC frequently reference the need for training of professionals as a component of their continuing professional development (Enderby et al., 2013; Communication Champion, 2010). Specific training for professionals working with children with severe/complex speech, language and communication needs (SLCN) is also widely recommended (Department for Children, Schools and Families, 2008). More widely, professionals and parents have reported that training contributes to positive outcomes for AAC users (Soto et al., 2001). For example, in a survey of AAC users and family members, training for families and teachers was identified as a critical factor facilitating positive outcomes in AAC system use (Lund \& Light, 2007). McMillan (2008) has also reported that AAC training for teachers was associated with positive outcomes for students using AAC. McMillian documented an increased rate of initiation using $A A C$ and generalisation and maintenance of $A A C$ device use for two months post-training.

The shift to supporting children with special educational needs (SEN) in mainstream schools has increased the proportion of professionals likely to encounter children who use AAC (Matthews, 2001). Speech and language therapists (SLTs) are often key in managing AAC system use, however in a survey of 320 SLTs, Matthews (2001) found that only $57 \%$ of therapists in the UK had received undergraduate training in AAC. Additionally, most SLTS classified their knowledge in supporting AAC technologies as either 'none' (31\%) or 'general knowledge/awareness' (37\%). It is reported that UK SLT undergraduates typically receive only 6-10 hours of AAC training (Communication Champion, 2010). This suggests a high and growing level of need for post-qualification training.

\subsection{Current Training Recommendations}

A range of recommendations have been made on UK provision of AAC services (Enderby et al., 2013; Communication Champion, 2010; Communication Matters, 2012). As yet, no consensus exists for the amount, delivery mode and content of AAC training for professionals. Recommendations by the Royal College of Speech and Language Therapists (RCSLT, 2011) focus primarily on training in relation to supporting AAC technology use. Enderby et al. (2013) explored the theme of AAC training, suggesting that training concentrates on 'AAC strategies, research and practice; AAC systems, methods and techniques and how to access and implement them; $A A C$ equipment and potential customisation and access options; and how to use and prepare the equipment for use.' ( $p$. 76). Similarly, Communication Matters (2012), the UK chapter of the International Society for AAC highlighted the need to train professionals on software, hardware, vocabulary and communication strategies.

Others have recommended training on enhancing the AAC user's communicative environment. Costigan and Light (2010) discussed a need to train professionals in supporting the wider range of participatory skills needed by an AAC user. They recommended that pre- 
qualification AAC training should develop professional skills in areas including assessment, intervention, AAC symbols and systems, cultural competence, problem-solving and collaborative skills, highlighting a likely need to train professionals in areas of AAC support beyond the operational knowledge of AAC technologies.

Recognition of the potential benefits of specifying aspects of training need is seen in the development of a framework for informing and profiling AAC knowledge and skills in staff across health, education and social services (IPAACKS; NHS Education for Scotland, 2014). Developed in Scotland, this framework was developed through review of relevant literature and consultation with key stakeholders including people with AAC. It outlines core values that should underpin the work of those supporting people who use AAC, and provides information on competency levels for staff across four skill levels, within eight skills areas, two of which focus on issues related to AAC technology (e.g. AAC technology preparation, adaption and implementation; AAC Technology management of resources). The authors suggest that this broad-based framework can be used by individuals and /or organisations to appraise and monitor staff skills sets. Another approach to framing the scope of AAC training is the World Health Organisation's International Classification of Functioning, Disability and Health (ICF; World Health Organisation (WHO), 2001). The ICF has been used widely to assess communication difficulties and their impact on daily life for people using AAC (Clarke, Newton, Petrides, Griffiths, Lysley \& Price, 2012; Price \& Clarke, 2011; Threats \& Worrall, 2004). This biopsychosocial model has been applied to many aspects of communication impairment and examines the interactions between an individual's health conditions, body functions and structures, activities and participation. Furthermore, it considers environmental and personal factors that may influence an individual (WHO, 2001).

More recently, the International Classification of Functioning, Disability and Health Children \& Youth Version (ICF-CY; WHO, 2007) has been used as a framework for assessment of children and young people who use AAC (Rowland et al., 2012; Clarke, Newton, Petrides, Griffiths, Lysley \& Price, 2012; Griffiths \& Price, 2011). Rowland and colleagues proposed that using the ICF-CY in the AAC field may encourage professionals working in $A A C$ to consider a wider range of environmental factors that influence young communicators, as well as the functional communication skills needed for activity and participation. The ICF has also been used to frame recommendations for training provision in AAC, computer access and environmental control, reflecting multiple issues in effective support for AAC users beyond knowledge of AAC devices themselves (Gresswell \& Hoogerwerf, 2007).

\subsection{Summary and Research Questions}

There is a lack of consensus on the quantity or content of AAC training for professionals working with people using AAC. Consequently, there is a risk that needs may not be understood or fully met. Evidence suggests that $A A C$ training for pre-qualification professionals is limited and there is no information on the content or quantity of AAC postqualification training delivered for professionals across England. This paper therefore sought to address the following question: What is the current overview of AAC training provision-and requirements in England? 


\section{Methodology}

\subsection{Questionnaire measure}

The questionnaire was developed through expert consensus in the research team and a stakeholder focus group, comprising service users, service providers, suppliers and a service commissioner. It was then piloted with four clinical AAC services and adapted in response to feedback from this group. This method was chosen because it enabled a large number of organisations to respond promptly and allowed national data to be collected easily and accurately. The survey comprised two sections: (i) information concerning AAC training provision training frequency, length, type, content and cost, trainee occupations and numbers, and future training priorities, and (ii) information concerning the survey respondents - service type, geographical area. Responses were made largely via closed multiple choice or rating scales, to enable comparison between responses. Areas of training content presented in multiple choice options reflected the ICF framework's domains. The first author linked the training content with ICF categories and established 71\% agreement with the other researchers, with $100 \%$ agreement following further discussion. A copy of the questionnaire is available from the authors on request.

\subsection{Procedure}

Participants were identified via Communication Matters charity specialist AAC provider database, and from the national AAC service database concurrently being developed under the auspices of the Department for Education-funded AAC Grants Project (2012-2013), which aimed to locate and survey all services providing AAC in England. An invitation to engage in the study was emailed to all services identified and a series of reminders were sent. Participants were directed to the online survey, which was open for eight weeks. Data was anonymised as appropriate and stored securely. Participants were informed that completing the questionnaire gave consent for storage of responses by submitting the survey. Ethical review for the project was sought from the university ethics board. The ethics board advised that, given the methods involved in the study, review was not required because the study involved no change to standard clinical service.

\subsection{Participants}

The questionnaire was sent to 187 service providers in England. Responses were received from 98 clinical services. Commercial AAC services, independent AAC services and Higher Education Institutes were also invited to engage in the study. The responses provided by these organisations are not contained within this article.

\subsection{Data Analysis}

All questionnaire responses were collated and stored directly in a SurveyMonkey ${ }^{\mathrm{TM}}$ database. The questionnaire data was transferred to Microsoft Excel for quantitative and qualitative analysis. Free text entries were analysed by the research team. Key issues identified were compared in order to agree final themes. Descriptive statistics summarised participant responses and free text responses were analysed using the principles and methods of thematic analysis (Braun \& Clarke, 2006). Key themes were identified by the research team with ongoing refinements to ensure that all free text comments were addressed. While prevalence of need for AAC in the UK is estimated at $0.5 \%$, accurate 
information is not available for the actual population currently served by AAC services. Therefore, an a priori assumption was made that that need for training is broadly equivalent across regions.

\section{Results}

\subsection{Respondent demographics}

Ninety-eight clinical service training providers in England responded to the survey, including NHS, education and charities providing established clinical services $(n=98$; adult services= $38 \%$; paediatric services $=48 \%$, combined adult and paediatric services $=13 \%$; unspecified $=$ $1 \%)$.

Table 1 shows the geographical distribution of responses across the 10 Specialised Commissioning Hub $(\mathrm{SCH})$ regions in England. The survey received responses from each region, however the number of services represented in each $\mathrm{SCH}$ region varies.

[Table 1.]

Clinical services classified the reach of their service as local, regional or national (local $=51 \%$, regional $=11 \%$, national $=6 \%$, other/unspecified $=32 \%$ ). Where respondents classified their service reach at more than one level, the widest reach level only was recorded.

Services predominantly delivered AAC training to professionals in their own service or regional catchment area only (only professionals within the service/organisation $=36 \%$, only professionals within the regional catchment area $=38 \%$, professionals from anywhere $=9 \%$, other $=7 \%$, no response $=10 \%$ ).

The distribution of training to specific professional groups is shown in Table 2. The four most commonly trained professional groups for each subgroup of clinical services are highlighted.

[Table 2.]

Over half of the responding clinical services delivered training to speech and language therapists, teaching assistants and teachers, with $95 \%$ of paediatric clinical services delivering training to teaching assistants. Over a third of clinical services for adults provided training to nurses; a smaller proportion of paediatric services trained this population (34\% of adult services, $7 \%$ of paediatric services). A fifth or less of the responding clinical services delivered training to nurses, physiotherapists, managers, clinical technicians, social workers, psychologists, commissioners or doctors, with just $6 \%$ of total services training doctors.

\subsection{AAC training content}

The proportion of training delivered by service providers in each specified content topic are shown in Table 3, in order of percentage response from high to low. The most common area of training concerned use of specific AAC products, systems and technologies (27\%), although the proportion of training delivered on this topic varied notably across the sample (range $0-100 \%$ ). Introducing/awareness raising of AAC products, systems and technology 
(13\%) and aspects of language development and learning through AAC (12\%) were also subject areas which received relatively high levels of attention. In comparison, all other subject areas were poorly represented, with the percentage of training in outcome measurement markedly low, at less than $1 \%$ of overall training activity.

[Table 3.]

The areas of training content were categorised as relating to the impairment, activity, participation or environment of an AAC user, as follows:

[Table 4.]

These definitions were based on the ICF model (WHO, 2001). Measuring outcomes was found to fall outside the specific components of the ICF model, as outcomes might relate to any aspect of impairment, activity, participation or environment.

As shown in Table 3, whilst a large percentage of training was delivered on specific areas of the environment, training was also frequently provided on aspects of the AAC user's impairment and activity. Notably, training on the participation of AAC users appeared to be less frequently delivered.

\subsection{Perceived priorities for future training}

Respondents ranked 15 subject areas for priority for future training provision ( $1=$ highest priority, $15=$ lowest priority). Overall, the subject area receiving the highest priority ranking was use of specific AAC products, systems and technology (mean ranking score $=\mathbf{5 . 3 5}$ ). Other highly ranked subject areas were adapting the environment to facilitate AAC use (mean ranking score $\mathbf{5 . 9 2}$ ) and introducing/awareness raising of AAC products (mean ranking score $=6.05$ ). All three of these high priority subject areas target the environment of an AAC user, rather than the impairment, activity or participation of the individual.

Use of specific AAC products, systems and technology and introducing/awareness raising of AAC products are both rated as high priority for future training and are two of the three subject areas in which services reported delivering the highest percentage of training.

Those rated as lowest priority were training in: supporting social/community participation of people who use AAC, measuring outcomes and AAC service delivery and funding. This is in line with the profile of current training, as respondents reported relatively less training activity in these subject areas.

The high level of variation in the priority ranks given by the respondents is noteworthy. All training subject areas were ranked at a minimum of 10 different levels of priority across respondents.

\subsection{Training level}

The level of AAC training was classified by respondents according to three bands:

Foundation: Aimed at those new to AAC and typically introducing general and basic concepts in AAC and/or providing an overview of the area. 
Intermediate: Aimed at those with basic knowledge of, and some experience in, AAC. Training would typically provide comprehensive study of a particular area of AAC or its application to a particular group of people.

Advanced: Aimed at those with a good level of knowledge and a variety of experiences in AAC. Training at this level will target highly specialist issues and/or wider service delivery issues.

Training was found to be predominantly provided at a foundation level, across each subject area (71\%). A distinctly smaller proportion of training was delivered at intermediate level (25\%) and less training still was delivered at advanced level (4\%).

\subsection{Mode of training}

The majority of clinical services delivered training entirely face-to-face with only two respondents reporting use of web-based learning (entirely face-to-face $=80 \%$, mostly faceto-face with some web-based learning/support $=3 \%$, mostly web-based (e.g. online activities) with some face-to-face $=0 \%$, entirely web-based $=0 \%$, other $=2 \%$, no response $=$ $15 \%)$.

\section{Discussion}

The aim of this paper was to identify the profile of post-qualification AAC training delivered by clinical services in England. This was based on the recognition that AAC services and technologies are evolving rapidly and that available evidence does not provide robust understanding of the amount and type of training being provided and the learning support needs for professionals who may encounter AAC in their clinical work. The results indicate variability in the training delivered, together with a tendency towards face-to-face foundation level training.

\subsection{Training content and perceived priorities}

Approximately one third of training across services focused on using specific AAC technology; however the range of training priorities was diverse. This may be due to the limited policy and recommendations available to guide priorities for training, or may reflect the heterogeneous nature of the client group and variable training needs for AAC professionals. Notably, whilst 'adapting the environment to facilitate AAC use' received a relatively high priority rating from respondents, this area was reported to receive very little attention during training provision.

\subsection{Focus on training to support technology use}

Recommendations for post-qualification AAC training often focus on the use of specific AAC technologies (e.g. Enderby et al., 2013; RCSLT, 2011). However, other essential aspects of knowledge and skill in relation to supporting the holistic needs of people who use AAC are, it seems, not fully addressed. The content most frequently covered in post-qualification training did not fully reflect the breadth of areas covered in the ICF model, and thus the full potential needs of AAC users and their families.

The emphasis on AAC technology, operational skills and/or an introduction to AAC corresponds with data on the content of pre-qualification courses in the United States (Costigan and Light; 2010). This is of relevance as AAC researchers report concerns that the 
focus on technology is being prioritised over the focus on the communication skills and needs of the individual (Light \& McNaughton, 2013). Indeed, in a study of long-term outcomes of AAC provision, five out of seven people using AAC who were interviewed reported that $A A C$ can function as a barrier to communication, and that intervention should best be driven by participation goals, rather than technology use (Lund \& Light, 2007).

\subsection{Supporting the environment and participation of the AAC user}

Limited training appeared to be provided for many environmental and participation factors such as supporting interactions with significant others, adapting the environment, AAC for daily living and the acceptance, and rejection and abandonment of AAC. There is currently little research on the effectiveness of AAC training for professionals across the ICF model's various domains, however some evidence suggests that environmental training on topics beyond use of AAC technology can result in maintained improvement of AAC use in the short term (McMillan, 2008). Furthermore, research has suggested that AAC training focusing on elements of participation such as the attitudes and skills of conversation partners may be beneficial. The attitudes of family, peers, professionals and society are understood to impact on participation levels for AAC users (McCarthy \& Light, 2005). According to Lund and Light (2007), it is likely that positive attitudes to AAC use will result in expectations of success and a supportive and inclusive environment. This suggests that training professionals to advocate positive attitudes towards AAC use in their settings may result in better outcomes for AAC users. However, as an increasing range of mainstream technology is used to provide AAC options, several researchers have proposed that there is increased public awareness and social acceptance of AAC (McNaughton \& Light, 2013; Shane et al., 2012). Questions remain as to the potential shifts in societal attitudes towards $A A C$ and people who use AAC as mainstream technologies are used for AAC purposes, and the ways in which training may promote positive attitudinal change.

\subsection{Outcome measurement in AAC}

The Bercow Report (2008) found that insufficient measurements exist to provide service commissioners with evidence of outcomes in speech and language therapy, and recommended continual evaluation of progress to ensure positive outcomes for clients. Outcome measurement was reported to be given minimal attention in the training provided by survey respondents in this study. This limited focus on outcome measurement has also been previously noted (Lund \& Light, 2007). Furthermore, Lund and Light (2007) reported that AAC users and family members highlighted limited attention to goals and over-focus on intervention as a barrier to positive outcomes for people using AAC during interviews. The low priority given to training in AAC outcome measurement may reflect a need for this training to be developed and delivered in this area. It is possible also that the low reported training on outcomes specific to $A A C$ but be a consequence of the respondents applying established service-wide procedures for outcome measurement to the AAC context. Given the multifaceted and specific demands of AAC intervention, it may be reasonable to suggest that reflection on outcome measurement in the AAC context would benefit from specific consideration by service providers.

\subsection{Training level}

The respondents reported that they primarily delivered foundation level training. As the topics of AAC equipment, language development and learning, and some aspects of the 
environment and were most commonly delivered in training by the survey respondents, this may reflect a model of AAC training delivery where knowledge of these topics is regarded as foundation or basic knowledge of AAC. This suggests that elements of the environment such as supporting interactions with significant others and adapting the environment; elements of participation such as AAC for daily living, and acceptance, rejection and abandonment of $A A C$, and outcome measurement comprise the more intermediate/advanced knowledge related to AAC. Further multidisciplinary work will be required to identify the need for, and potential content of, intermediate and advanced training in AAC. Given that continuing professional development is integral to professions working with individuals who use AAC, the lack of training at an intermediate or advanced level is an area of considerable concern.

\subsection{Delivery mode}

With the growing use of information technology in the workplace, a rising trend towards web-based learning for post-qualification professionals has been observed. However, only a small proportion of the training delivered by the survey respondents in this study was given online.

Advantages of web-based learning are well-purported; in particular that web-based learning can be achieved regardless of distance from trainer, that participants can access training according to their own schedule and opportunities for individualised learning where participants progress at their own pace (Cook, 2007). Web-based training can also support increased training reach (Lebel et al., 2005). This may be of specific benefit in the field of $A A C$, where specialist services are geographically remote from the services that they may support. In these instances, web-based learning could result in significant savings relating to length and cost of travel. This is an area that would benefit from further exploration, in order to maximise professional efficiency and opportunities for staff development in the area of AAC.

\subsection{Limitations}

Limitations for this study include the sample method, as sampling was self-selected and the researchers did not contact non-respondents to establish why they did not contribute to the survey. With no register of clinical AAC services in England, it was not possible to calculate the percentage of eligible services which responded to the questionnaire. Furthermore, there was a bias in the distributional spread of responses with a greater number of responses from London and the South West. Nevertheless, the study did retain a large sample size and the survey has revealed some important insights into the training provision for professionals working in England with children and adults using AAC. It is possible that clinical services are focusing on aided technology training and that the area of unaided or low tech training may be receiving less attention (lacono et al., 2011). This would benefit from further exploration in future research. Additionally, information was not collected regarding the professionals working in the teams surveyed, and it may be that the make-up of professionals in those teams influenced their views on training priorities. A further limitation is that information on training to parents, carers and people who use AAC was not gathered. More research into this area may provide valuable insights into the support parents, carers and users receive.

Professionals responding to the questionnaire were not asked to document the amount of training they provide on using AAC to access social media. However, as a growing area of 
interest with potential benefits for AAC users (Raghavendra et al., 2015), it warrants consideration in post- and pre-qualification professional training.

\subsection{Summary Conclusion}

There is no consensus on the amount or content of AAC training which professionals in England must receive in order to provide best possible services to people using AAC. Existing research suggests that $A A C$ training for pre-qualification professionals is limited and this paper has identified significant variation in the amount and type of post-qualification AAC training provided by clinical services. Training provided by respondents was predominantly face-to-face and delivered at a foundation level. Respondents reported diverse priorities for future AAC training; notably, these priorities did not consistently match the current training content.

There is potential for the re-examination of AAC training provision to professionals across a broad range of areas. Costigan and Light (2010) have recommended that specific and measurable competencies for AAC training should be established in order to enhance professional knowledge and skills against recognised benchmarks, and frameworks such as the IPACCKS (NHS Education for Scotland, 2014) have been developed for this purpose. Recommendations for effective training delivery models and length and dosage of training in AAC would allow professionals to ensure they have the training to support AAC users. To develop AAC training in England, further information is needed on whether current AAC training is effective, to determine the maintenance of skills learnt and the impact of this training. In particular, evidence relating to the efficacy of AAC training across ICF domains would seem to support recommendations for potential AAC training content for professionals.

\section{References}

Braun, V. and Clarke, V. (2006), "Using thematic analysis in psychology", Qualitative
Research in Psychology, Vol. 3 No 2, pp. 77-101.
Clarke, M. T., and McConachie, H. (2001), "Views of young people using augmentativ and alternative communication systems", International Journal of Language and Communication Disorders, Vol. 36, No. 1, pp.107-115.

Clarke, M. T., Newton, C., Petrides, K. V., Griffiths, T., Lysley, A., and Price, K. (2012), "An examination of relations between participation, communication and age in children with complex communication needs", Augmentative and Alternative Communication, Vol. 28 No 1, pp. 44-51.

Clarke, M. T., and Price, K. (2012), "Augmentative and alternative communication for children with cerebral palsy", Paediatrics and Child Health, Vol. 22 No. 9, pp. 367-371.

Clarke, M. T., Price, K., and Griffiths, T. (2016). "Augmentative and alternative communication for children with cerebral palsy", Paediatrics and Child Health, Vol. 26 No 9, pp. 373-377.

Clarke, M. T., Price, K., and Jolleff, N. (2012), "Augmentative and alternative communication" in Kersner, M., and Wright, J. (Eds.), Speech and Language Therapy: The Decision Making Process When Working with with Children, Fulton, London, pp. 201-209.

Communication Champion (2010), "Augmentative and alternative communication: a report on provision for children and young people in England", A report from the Office of the Communication Champion and Council, London. 
Communication Champion (2011), "Specialised AAC provision: Commissioning national services" A report from the Office of the Communication Champion and Council, London.

Communication Matters (2012), "AAC Service Standards", A report from Communication Matters, Leeds.

Cook, D. A. (2007), "Web-based learning: pros, cons and controversies", Clinical Medicine Vol. 7, pp. 37-42.

Costigan, A., and Light, J. (2010), "A Review of Preservice Training in Augmentative and Alternative Communication for Speech-Language Pathologists, Special Education Teachers, and Occupational Therapists", Assistive Technology: The Official Journal of RESNA, Vol. 22 No. 4, pp. 200-212.

Creer, S., Enderby, P., Judge, S. and John, A. (2016), "Prevalence of People Who Could Benefit From Augmentative and Alternative Communication (AAC) in the UK: Determining the Need", International Journal of Language and Communication Disorders, Vol. 51 No. 6,pp. 639-653.

Department for Children, Schools and Families (2008), "The Bercow Report: A review of services for children and young people (0-19) with speech, language and communication needs", A report from Department for Children, Schools and Families, London.

Department for Education (2013), "The Future of AAC Services in England: A framework for equitable and effective commissioning", a report from the Department for Education, London.

Enderby, P., Judge, S., Creer, S., and John, A. (2013), "Examining the need for, and provision of, AAC in the United Kingdom", a report from Communication Matters, Leeds.

Ganz, J. B. (2015), "AAC Interventions for Individuals with Autism Spectrum Disorders: State of the Science and Future Research Directions", Augmentative and Alternative Communication, Vol. 31 No. 3, pp. 203-214.

Gresswell, A. and Hoogerwerf, E. (2007), "Guidelines for Lifelong Learning in Assistive Technology. Communication, computer access and environmental control", KPT Consortium, AIAS Bologna onlus, available at: http://www.at4inclusion.org/kpt/book+guidelines ENG.pdf (accessed 19 August 2016).

Griffiths, T., and Price, K. (2011), "A proposed framework for decision-making for assistive communication technology support: many perspectives, but one common goal", Journal of Assistive Technologies, Vol. 5 No. 4, pp. 242-248.

Hynan, A., Goldbart, J. and Murray, J. (2015), "A grounded theory of Internet and social media use by young people who use augmentative and alternative communication (AAC)", Disability and Rehabilitation, Vol. 37 No. 17, pp. 1559-1575.lacono, T., Lyon, K. and West, D. (2011), "Non-electronic communication aids for people with complex communication needs", International Journal of Speech Language Pathology, Vol. 13 No. 5, pp. 399-410.

Lebel, T., Olshtain, E. and Weiss, P. (2005), "Teaching Teachers about Augmentative and Alternative Communication: Opportunities and Challenges of a Web-Based Course", Augmentative and Alternative Communication, Vol. 21 No. 4, pp. 264-277.

Light, J. and McNaughton, D. (2012), "Supporting the communication, language, and literacy development of children with complex communication needs: State of the science and future research", Assistive Technology, Vol. 24, pp. 34-44.

Light, J. and McNaughton, D. (2013), "Putting People First: Re-Thinking the Role of Technology in Augmentative and Alternative Communication Intervention", Augmentative and Alternative Communication, Vol. 29 No. 4, pp. 299-309. 
Lund, S., and Light, J. (2007), "Long-term Outcomes for Individuals Who Use Augmentative and Alternative Communication: Part III - Contributing Factors", Augmentative and Alternative Communication, Vol. 23 No. 4, pp. 323-335.

Matthews, R. (2001), “A survey to identify therapists' high-tech AAC knowledge, application and training", International Journal of Language and Communication Disorders, Vol. 36, pp. 64-69.

McMillan, J. (2008), "Teachers Make It Happen: From Professional Development to Integration of Augmentative and Alternative Communication Technologies in the Classroom", Australasian Journal of Special Education, Vol. 32 No. 2, pp. 199-211.

McCarthy, J., and Light, J. (2005), "Attitudes towards individuals who use augmentative and alternative communication: research review", Augmentative and Alternative Communication, Vol. 21 No. 1, pp. 41-55.

Mirenda, P. (2003), "Toward functional augmentative and alternative communication for students with autism: manual signs, graphic symbols, and voice output communication aids", Language, Speech, and Hearing Services in Schools, Vol. 34, pp. 203-216.

NHS Education for Scotland (2014), "IPAACKS: informing and profiling AAC knowledge and skills", a framework from NHS Education for Scotland, Edinburgh.

National Institute for Health and Care Excellence (NICE) (2016) "Motor neurone disease: assessment and management (NG42)", a report from NICE, London.

Price, K., and Clarke, M. T. (2011), "Developing total communication systems for children with oro-motor disorders", in Roig Quilis, M., and Pennington, L. (Eds.), Oro-motor disorders in childhood, Viguera, Barcelona, pp. 285-298.

Raghavendra, P., Newman, L., Grace, E. and Wood, D. (2015), “Enhancing social participation in young people with communication disabilities living in rural Australia: outcomes of a home-based intervention for using social media", Disability and Rehabilitation, Vol. 37 No. 17, pp. 1576-1590

RCSLT (2011), "Resource manual for commissioning and planning services for SLCN: Augmentative and Alternative Communication (AAC)", a report from the RCSLT, London.

Rowland, C., Fried-Oken, M., Steiner, S., Lollar, D., Phelps, R., Simeonsson, R., and Granlund, M. (2012), "Developing the ICF-CY for AAC Profile and Code Set for Children Who Rely on AAC", Augmentative and Alternative Communication, Vol. 28 No. 1, pp. 21-32.

Shane, H., Laubscher, E., Schlosser, R. Flynn, S., Sorce, J., and Abramson, J. (2012), "Applying Technology to Visually Support Language and Communication in Individuals with Autism Spectrum", Disorders Journal of Autism and Developmental Disorders, Vol. 42, pp. 1228-1235.

Soto, G., Muller, E., Hunt, P. and Goetz, L. (2001), "Critical issues in the inclusion of students who use augmentative and alternative communication: an educational team perspective", Augmentative and Alternative Communication, Vol. 17, pp. 62-72.

Threats, T. T. and Worrall, L. (2004), "Classifying communication disability using the ICF", Advances in Speech-Language Pathology, Vol. 6 No. 1, pp. $53-62$.

World Health Organisation (2001), "International classification of functioning, disability and health", a report from the World Health Organisation, Geneva. 


\begin{tabular}{|l|c|}
\hline $\begin{array}{l}\text { Specialised Commissioning Hub (SCH) regions in } \\
\text { England }\end{array}$ & Number of responding services \\
\hline East Midlands & 5 \\
\hline East of England & 6 \\
\hline London & 19 \\
\hline $\begin{array}{l}\text { North East, North Cumbria and the Hambleton } \\
\text { and Richmondshire districts of North Yorkshire }\end{array}$ & 4 \\
\hline North West & 6 \\
\hline South East Coast & 7 \\
\hline South West & 16 \\
\hline Thames Valley and Wessex & 9 \\
\hline West Midlands & 9 \\
\hline Yorkshire and the Humber & 12 \\
\hline All of England & 5 \\
\hline \multicolumn{1}{|c|}{ Total } & 98 \\
\hline
\end{tabular}




\begin{tabular}{|l|l|l|l|l|}
\hline & $\begin{array}{l}\text { Percentage of } \\
\text { overall clinical } \\
\text { services } \\
\text { providing } \\
\text { training to each } \\
\text { profession } \\
\text { (n=85) }\end{array}$ & $\begin{array}{l}\text { Percentage of } \\
\text { adult clinical } \\
\text { services } \\
\text { providing } \\
\text { training to } \\
\text { each } \\
\text { profession } \\
(\mathrm{n}=32)\end{array}$ & $\begin{array}{l}\text { Percentage } \\
\text { of paediatric } \\
\text { clinical } \\
\text { services } \\
\text { providing } \\
\text { training to } \\
\text { each } \\
\text { profession } \\
(\mathrm{n}=42)\end{array}$ & $\begin{array}{l}\text { Percentage of } \\
\text { mixed clinical } \\
\text { services } \\
\text { providing } \\
\text { training to each } \\
\text { profession } \\
\text { (n=11) }\end{array}$ \\
\hline $\begin{array}{l}\text { Speech and language } \\
\text { therapists }\end{array}$ & $62 \%$ & $47 \%$ & $64 \%$ & $100 \%$ \\
\hline Teaching assistants & $60 \%$ & $13 \%$ & $95 \%$ & $64 \%$ \\
\hline Teachers & $53 \%$ & $9 \%$ & $83 \%$ & $64 \%$ \\
\hline Care assistants & $48 \%$ & $66 \%$ & $33 \%$ & $55 \%$ \\
\hline $\begin{array}{l}\text { Occupational } \\
\text { therapists }\end{array}$ & $36 \%$ & $38 \%$ & $31 \%$ & $55 \%$ \\
\hline Other & $24 \%$ & $19 \%$ & $29 \%$ & $18 \%$ \\
\hline Nurses & $20 \%$ & $34 \%$ & $7 \%$ & $27 \%$ \\
\hline Physiotherapists & $20 \%$ & $19 \%$ & $19 \%$ & $27 \%$ \\
\hline Managers & $16 \%$ & $16 \%$ & $12 \%$ & $36 \%$ \\
\hline Social workers & $13 \%$ & $25 \%$ & $5 \%$ & $9 \%$ \\
\hline Clinical technicians & $12 \%$ & $9 \%$ & $10 \%$ & $27 \%$ \\
\hline Psychologists & $9 \%$ & $13 \%$ & $7 \%$ & $9 \%$ \\
\hline Commissioners & $7 \%$ & $3 \%$ & $5 \%$ & $27 \%$ \\
\hline Doctors & $6 \%$ & $3 \%$ & $5 \%$ & $18 \%$ \\
\hline
\end{tabular}




\begin{tabular}{|c|c|c|c|}
\hline $\begin{array}{l}\text { Overall clinical } \\
\text { services }\end{array}$ & Adult services & Paediatric services & Mixed services \\
\hline $\begin{array}{l}\text { Use of specific AAC } \\
\text { products, systems and } \\
\text { technology: } 27 \% \\
\text { (E) }\end{array}$ & $\begin{array}{l}\text { Use of specific AAC } \\
\text { products, systems and } \\
\text { technology: } 27 \% \\
\text { (E) }\end{array}$ & $\begin{array}{l}\text { Use of specific AAC } \\
\text { products, systems and } \\
\text { technology: } 30 \% \\
\text { (E) }\end{array}$ & $\begin{array}{l}\text { Use of specific AAC } \\
\text { products, systems and } \\
\text { technology: } 21 \% \\
\text { (E) }\end{array}$ \\
\hline $\begin{array}{l}\text { Introducing/awareness } \\
\text { raising of AAC } \\
\text { products, systems and } \\
\text { technology: } 13 \% \\
\text { (E) }\end{array}$ & $\begin{array}{l}\text { Introducing/awareness } \\
\text { raising of AAC } \\
\text { products, systems and } \\
\text { technology: } 14 \% \\
\text { (E) }\end{array}$ & $\begin{array}{l}\text { Language } \\
\text { development and } \\
\text { learning through AAC: } \\
19 \% \\
\text { (A) }\end{array}$ & $\begin{array}{l}\text { Introducing/awareness } \\
\text { raising of AAC } \\
\text { products, systems and } \\
\text { technology: } 15 \% \\
\text { (E) }\end{array}$ \\
\hline $\begin{array}{l}\text { Language } \\
\text { development and } \\
\text { learning through AAC: } \\
12 \% \\
\text { (A) }\end{array}$ & $\begin{array}{l}\text { AAC use for daily living } \\
\text { activities: } 11 \% \\
\text { (A) }\end{array}$ & $\begin{array}{l}\text { Introducing/awareness } \\
\text { raising of AAC } \\
\text { products, systems and } \\
\text { technology: } 11 \% \\
\text { (E) }\end{array}$ & $\begin{array}{l}\text { Language } \\
\text { development and } \\
\text { learning through AAC: } \\
12 \% \\
\text { (A) }\end{array}$ \\
\hline $\begin{array}{l}\text { Cognition and } \\
\text { language: } 7 \% \\
\text { (I) }\end{array}$ & $\begin{array}{l}\text { Cognition and } \\
\text { language: } 9 \% \\
\text { (I) }\end{array}$ & $\begin{array}{l}\text { Adapting the } \\
\text { environment to } \\
\text { facilitate AAC use: } 8 \% \\
\text { (E) }\end{array}$ & $\begin{array}{l}\text { Cognition and } \\
\text { language: } 9 \% \\
\text { (I) }\end{array}$ \\
\hline $\begin{array}{l}\text { AAC use for daily living } \\
\text { activities: } 6 \%\end{array}$ & $\begin{array}{l}\text { Developing the } \\
\text { interpersonal } \\
\text { interaction skills of } \\
\text { significant others: } 9 \% \\
\text { (P) }\end{array}$ & $\begin{array}{l}\text { Developing the } \\
\text { interpersonal } \\
\text { interaction skills of } \\
\text { people using AAC: } 6 \% \\
\text { (P) }\end{array}$ & $\begin{array}{l}\text { Seating and } \\
\text { positioning for AAC } \\
\text { use: } 7 \% \\
\text { (A) }\end{array}$ \\
\hline $\begin{array}{l}\text { Adapting the } \\
\text { environment to } \\
\text { facilitate AAC use: } 6 \% \\
\text { (E) }\end{array}$ & $\begin{array}{l}\text { Developing the } \\
\text { interpersonal } \\
\text { interaction skills of } \\
\text { people using AAC: } 6 \% \\
\text { (P) }\end{array}$ & $\begin{array}{l}\text { Motor and sensory } \\
\text { function: } 6 \%\end{array}$ & $\begin{array}{l}\text { AAC service delivery } \\
\text { and funding: } 6 \%\end{array}$ \\
\hline $\begin{array}{l}\text { Developing the } \\
\text { interpersonal } \\
\text { interaction skills of } \\
\text { people using AAC: } 6 \% \\
\text { (P) }\end{array}$ & $\begin{array}{l}\text { Adapting the } \\
\text { environment to } \\
\text { facilitate AAC use: } 5 \% \\
\text { (E) }\end{array}$ & $\begin{array}{l}\text { Cognition and } \\
\text { language: } 5 \% \\
\text { (I) }\end{array}$ & $\begin{array}{l}\text { Developing the } \\
\text { interpersonal } \\
\text { interaction skills of } \\
\text { significant others: } 6 \% \\
\text { (P) }\end{array}$ \\
\hline $\begin{array}{l}\text { Developing the } \\
\text { interpersonal } \\
\text { interaction skills of } \\
\text { significant others: } 6 \% \\
\text { (P) }\end{array}$ & $\begin{array}{l}\text { Supporting } \\
\text { social/community } \\
\text { participation of people } \\
\text { who use AAC: } 5 \% \\
\text { (P) }\end{array}$ & $\begin{array}{l}\text { Developing the } \\
\text { interpersonal } \\
\text { interaction skills of } \\
\text { significant others: } 4 \% \\
\text { (P) }\end{array}$ & $\begin{array}{l}\text { Adapting the } \\
\text { environment to } \\
\text { facilitate AAC use: } 5 \% \\
\text { (E) }\end{array}$ \\
\hline $\begin{array}{l}\text { Motor and sensory } \\
\text { function: } 4 \%\end{array}$ & $\begin{array}{l}\text { Motor and sensory } \\
\text { function: } 4 \%\end{array}$ & $\begin{array}{l}\text { Seating and } \\
\text { positioning for AAC } \\
\text { use: } 4 \% \\
\text { (A) }\end{array}$ & $\begin{array}{l}\text { Supporting } \\
\text { social/community } \\
\text { participation of people } \\
\text { who use AAC: } 5 \% \\
\text { (P) }\end{array}$ \\
\hline
\end{tabular}




\begin{tabular}{|c|c|c|c|}
\hline $\begin{array}{l}\text { Seating and } \\
\text { positioning for AAC } \\
\text { use: } 3 \% \\
\text { (A) }\end{array}$ & $\begin{array}{l}\text { AAC service delivery } \\
\text { and funding: } 3 \%\end{array}$ & $\begin{array}{l}\text { AAC use for daily living } \\
\text { activities: } 3 \% \\
\text { (A) }\end{array}$ & $\begin{array}{l}\text { AAC use for daily living } \\
\text { activities: } 4 \% \\
\text { (A) }\end{array}$ \\
\hline $\begin{array}{l}\text { Supporting } \\
\text { social/community } \\
\text { participation of people } \\
\text { who use AAC: } 3 \% \\
\text { (P) }\end{array}$ & $\begin{array}{l}\text { Language } \\
\text { development and } \\
\text { learning through AAC: } \\
3 \% \\
\text { (A) }\end{array}$ & $\begin{array}{l}\text { Supporting } \\
\text { social/community } \\
\text { participation of people } \\
\text { who use AAC: } 2 \% \\
\text { (P) }\end{array}$ & $\begin{array}{l}\text { Developing the } \\
\text { interpersonal } \\
\text { interaction skills of } \\
\text { people using AAC: } 4 \% \\
\text { (P) }\end{array}$ \\
\hline $\begin{array}{l}\text { AAC service delivery } \\
\text { and funding: } 2 \%\end{array}$ & $\begin{array}{l}\text { Acceptance, rejection } \\
\text { and abandonment of } \\
\text { AAC: } 2 \% \\
\text { (A) }\end{array}$ & $\begin{array}{l}\text { Managing others' } \\
\text { attitudes towards } \\
\text { people who use AAC: } \\
1 \% \\
\text { (E) }\end{array}$ & $\begin{array}{l}\text { Acceptance, rejection } \\
\text { and abandonment of } \\
\text { AAC: } 2 \% \\
\text { (A) }\end{array}$ \\
\hline $\begin{array}{l}\text { Acceptance, rejection } \\
\text { and abandonment of } \\
\text { AAC: } 1 \% \\
\text { (A) }\end{array}$ & $\begin{array}{l}\text { Seating and } \\
\text { positioning for AAC } \\
\text { use: } 1 \% \\
\text { (A) }\end{array}$ & $\begin{array}{l}\text { Measuring outcomes: } \\
1 \%\end{array}$ & $\begin{array}{l}\text { Managing others' } \\
\text { attitudes towards } \\
\text { people who use AAC: } \\
2 \% \\
\text { (E) }\end{array}$ \\
\hline $\begin{array}{l}\text { Managing others' } \\
\text { attitudes towards } \\
\text { people who use AAC: } \\
1 \% \\
\text { (E) }\end{array}$ & $\begin{array}{l}\text { Managing others' } \\
\text { attitudes towards } \\
\text { people who use AAC: } \\
<1 \% \\
\text { (E) }\end{array}$ & $\begin{array}{l}\text { AAC service delivery } \\
\text { and funding: }<1 \%\end{array}$ & $\begin{array}{l}\text { Motor and sensory } \\
\text { function: } 2 \%\end{array}$ \\
\hline $\begin{array}{l}\text { Measuring outcomes: } \\
<1 \%\end{array}$ & $\begin{array}{l}\text { Measuring outcomes: } \\
<1 \%\end{array}$ & $\begin{array}{l}\text { Acceptance, rejection } \\
\text { and abandonment of } \\
\text { AAC: }<1 \% \\
\text { (A) }\end{array}$ & $\begin{array}{l}\text { Measuring outcomes: } \\
<1 \%\end{array}$ \\
\hline \begin{tabular}{l|l} 
Key & I: Impairment
\end{tabular} & A: Activity & \\
\hline
\end{tabular}




\begin{tabular}{|c|c|c|c|}
\hline Impairment & Activity & Participation & Environmental factors \\
\hline $\begin{array}{l}\text { Motor and sensory } \\
\text { function } \\
\text { Cognition and } \\
\text { language }\end{array}$ & $\begin{array}{l}\text { AAC use for daily } \\
\text { living activities } \\
\text { Acceptance, } \\
\text { rejection and } \\
\text { abandonment of } \\
\text { AAC } \\
\text { Seating and } \\
\text { positioning for AAC } \\
\text { use } \\
\text { Language } \\
\text { development and } \\
\text { learning through } \\
\text { AAC }\end{array}$ & $\begin{array}{l}\text { Supporting } \\
\text { social/community } \\
\text { participation of } \\
\text { people who use } \\
\text { AAC } \\
\text { Developing the } \\
\text { interpersonal } \\
\text { interaction skills of } \\
\text { people using AAC }\end{array}$ & $\begin{array}{l}\text { Developing the } \\
\text { interpersonal } \\
\text { interaction skills of } \\
\text { significant others } \\
\text { Managing others' } \\
\text { attitudes towards } \\
\text { people who use AAC } \\
\text { Adapting the } \\
\text { environment to } \\
\text { facilitate AAC use } \\
\text { AAC service delivery } \\
\text { and funding } \\
\text { Introducing/awareness } \\
\text { raising of AAC } \\
\text { products, systems and } \\
\text { technology } \\
\text { Use of specific AAC } \\
\text { products, systems and } \\
\text { technology }\end{array}$ \\
\hline
\end{tabular}

